\title{
Mangiferin induces apoptosis in human ovarian adenocarcinoma OVCAR3 cells via the regulation of Notch3
}

\author{
BINGYU ZOU ${ }^{1}$, HAILIAN WANG ${ }^{2}$, YILONG LIU ${ }^{3}$, PING QI $^{4}$, TIANTIAN LEI ${ }^{5}$, MINGHAN SUN $^{1}$ and YI WANG $^{3,5}$ \\ ${ }^{1}$ Department of Gynecology, Sichuan Academy of Medical Science and Sichuan Provincial People's Hospital; \\ ${ }^{2}$ Institute of Organ Transplantation, Sichuan Academy of Medical Science and Sichuan Provincial People's Hospital; \\ Departments of ${ }^{3}$ Pharmacy, ${ }^{4}$ Pediatrics, Sichuan Academy of Medical Science and Sichuan Provincial People's Hospital, \\ Chengdu, Sichuan 610072; ${ }^{5}$ Department of Pharmacy, Medical School of University of Electronic Science \\ and Technology of China, Chengdu, Sichuan 610054, P.R. China
}

Received February 20, 2017; Accepted June 19, 2017

DOI: $10.3892 /$ or.2017.5814

\begin{abstract}
Ovarian cancer is the most lethal gynecological malignancy in the world. Our previous studies showed that mangiferin, purified from plant source, possessed antineoplasm effect on human lung adenocarcinoma A549 cells. This study aimed to determine the apoptosis-inducing effect of mangiferin on human ovarian carcinoma OVCAR3 cells. By in vitro studies, we found mangiferin significantly inhibited viability of OVCAR3 cells, and remarkably increased the sensitivity of OVCAR3 cells to cisplatin. In addition, the activation of caspase-dependent apoptosis was observed in mangiferin treated ovarian cancer cells. Importantly, we observed an obviously downregulated Notch expression after mangiferin treatment, indicating the crucial role of Notch in mangiferin mediated apoptosis. In contrast, overexpression of Notch3 abrogated the apoptosis-inducing efficacy of mangiferin, further demonstrating that mangiferin induced apoptosis via Notch pathway. Furthermore, OVCAR3 cell xenograft models revealed that mangiferin treatment inhibited tumor growth and expanded survival of tumor xenograft mice. Based on these results, we concluded that mangiferin could significantly inhibit the proliferation and induce apoptosis in OVCAR3 cells. Our study also suggested the anti-neoplasm effect of mangiferin might be via the regulation of Notch3. Taken together, by targeting cell apoptosis pathways and enhancing the response to cisplatin treatment, mangiferin may represent a potential new drug for the treatment of human ovarian cancer.
\end{abstract}

Correspondence to: Dr Yi Wang, Department of Pharmacy, Sichuan Academy of Medical Science and Sichuan Provincial People's Hospital, 32 West Ring Road, Chengdu, Sichuan 610072, P.R. China

E-mail: w_yi@yahoo.com

Key words: mangiferin, ovarian adenocarcinoma OVCAR3 cells, Notch3, $\beta$-catenin, PI3K/Akt/mTOR

\section{Introduction}

Ovarian cancer is highly aggressive and the most malignant gynecologic neoplasm in women (1). Ovarian epithelial cancer accounts for $90 \%$ of all ovarian cancers and is the leading cause of death (2). Despite the initial response to surgery and chemotherapy as carboplatin and paclitaxel, most tumors ultimately become drug resistant, which causes relapse for the patients $(3,4)$. Eventually the majority of the patients die from their disease, highlighting the need for the development of novel treatment to improve upon the current therapeutic options.

It is generally accepted that the activation of signaling pathways PI3K/Akt $(5)$, Wnt/ $\beta$-catenin $(6,7)$, Notch $(8,9)$ and Hedgehog (10) contributes to the pathogenesis of ovarian carcinomas. Among them, Notch signaling pathway has received special attention due to its crucial role in controlling cell differentiation, proliferation and apoptosis (11). In normal tissue, Notch signaling pathway is under strict temporal and spatial control during development (11). In contrast, Notch has been found to be aberrantly expressed in several malignancies (12), such as T-ALL (13), lung cancer (14), breast cancer (15) and ovarian cancer (16). However, the biological importance of Notch in carcinoma goes well beyond that. Notch3 overexpression may be related to chemoresistance, and inactivation of Notch 3 by $\gamma$-secretase inhibitor might abrogate drug resistance (17). Therefore, therapeutic new drugs targeting Notch signaling pathway might be a promising approach for the treatment of ovarian cancer.

Mangiferin, a C-glucosylxanthone (1,3,6,7-tetrahydroxyxanthone-C2- $\beta$ - $D$-glucoside), is isolated from the leaves, stem bark, fruit peels and root of Mangifera indica L. (18). Previous studies revealed the antioxidant (19), antitumor (20), anti-bacteria, antiviral and immunomodulatory activities (21) of mangiferin. Furthermore, studies on cancer therapy showed anti-neoplastic effects of mangiferin on lung cancer $(22,23)$, colon cancer $(23,24)$, leukemia $(22,25-28)$, lung cancer $(22,28)$ and prostate cancer (22). Studies on the mechanism of mangiferin-induced apoptosis of breast cancer suggested that the downregulation of MMP-7 and -9 might contribute to the anti-tumor effect of mangiferin. Besides the activation of $\beta$-catenin pathway in breast cancer cells was also inhib- 
ited by mangiferin (29). Our previous results demonstrated that mangiferin possessed anti-neoplastic effect by inducing caspase-dependent apoptosis and regulating signaling pathways of NF- $\kappa \mathrm{B}$ and cyclin B1 (30) in human lung carcinomas. However, up to now, no data on the anti-neoplastic effect of mangiferin on ovarian cancer have been reported. Herein, we show that mangiferin treatment could induce apoptosis via blocking or silencing Notch3, which is the crux of multiple cancer survival and proliferation pathways. Therefore, our current study on mangiferin offers a potential new strategy for the therapeutic intervention in ovarian cancer.

\section{Materials and methods}

Reagents. Mangiferin was purchased from Shanghai PureOne Technology (Shanghai, China). The purity of mangiferin was $>95 \%$, and the chemical structure is shown on Fig. 1A. Human Embryonic Kidney 293T cells, human ovarian adenocarcinoma OVCAR3 cells, CaOV3 cells, SKOV3 cells, endometrioid carcinoma TOV-112D cells, and clear cell carcinoma TOV-21G were purchased from American Type Culture Collection (ATCC, Manassas, VA, USA). Human ovarian adenocarcinoma A2780 cells were purchased from Procell Co. (Wuhan, China). RPMI-1640 medium and fetal bovine serum (FBS) was purchased from Gibco BRL (Grand Island, NY, USA). 3-(4,5-Dimetrylthiazol-2-yl)-2, 5-diphenyltetrazolium bromide (MTT, cat. no. M5655), dimethyl sulfoxide (DMSO, cat.no. D2650), paraformaldehyde (PFA, cat. no. 16005), cisplatin (USP grade, cat. no. 1134357), Annexin V-FITC Apoptosis detection kit (cat. no. APOAF), HEPES (cat. no. H3375), Triton X-100 (cat. no. H9284), 2 mmol/l sodium orthovanadate (cat. no. S6508), sodium fluoride (cat. no. S7920), $1 \mathrm{mmol} / 1$ edetic acid (cat. no. E9884), PMSF (cat. no. 78830), aprotinin (cat. no. A11530), leupeptin (cat. no. L2884) and rhodamine-123 were purchased from Sigma-Aldrich Chemical (St. Louis, MO, USA). Hoechst 33342 (cat. no. C1025) was purchased from Beyotime Chemicals (Suzhou, China). Rabbit polyclonal pro-caspase-3 (cat. no. sc-7148; 1:1,000 dilution), mouse monoclonal pro-caspase-9 (cat. no. sc-56073; 1:1,000 dilution), rabbit polyclonal Bax (cat. no. sc-493; 1:500 dilution), mouse monoclonal Bid (cat. no. sc- 135847; 1:1,000 dilution), rabbit polyclonal Bcl-2 (cat. no. sc-492; 1:1,000 dilution),

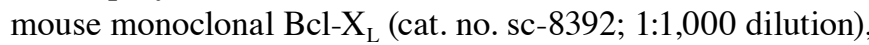
rabbit polyclonal PARP (cat. no. sc-7150; 1:1,000 dilution), rabbit polyclonal cytochrome c (cat. no. sc-7159; 1:1,000 dilution), mouse monoclonal cyclin D1 (cat. no. sc-450; 1:1,000 dilution), mouse monoclonal $\beta$-catenin (cat. no. sc-59737; 1:1,000 dilution), rabbit polyclonal Notch3 (NICD domain, cat. no. sc-5593; 1:1,000 dilution), mouse monoclonal Notch1 (cat. no. sc-376403; 1:1,000 dilution) and mouse monoclonal $\beta$-actin (cat. no. sc-47778; 1:5,000 dilution) purchased from Santa Cruz Biotechnology, Inc. (Santa Cruz, CA, USA). Mouse monoclonal PI3K p85 (cat. no. ab189403; 1:500 dilution), rabbit polyclonal phosphor-PI3K p85 (cat. no. ab182651; 1:500 dilution), rabbit polyclonal mTOR (cat. no. ab2732; 1:500 dilution) and rabbit polyclonal phospho-mTOR (S2448, cat. no. ab109268; 1:500 dilution) antibodies were from Abcam (Cambridge, MA, USA). Mouse monoclonal Akt (pan, cat. no. 2920; 1:500 dilution), rabbit polyclonal phospho-Akt (S473, cat. no. 4060; 1:500 dilution), rabbit polyclonal cleaved caspase-3 (cat. no. 9661; 1:500 dilution) and rabbit polyclonal cleaved caspase-9 (cat. no. 9509; 1:1,000 dilution), were purchased from Cell Signaling Technologies (Danvers, MA, USA). Horseradish peroxidase (HRP)-conjugated goat anti-mouse IgG polyclonal antibody (cat. no. 115-035-003) and HRP-conjugated goat anti-rabbit polyclonal IgG (cat. no. 111-035-003) were purchased from Jackson ImmunoResearch Laboratories.

Cell culture. Human Embryonic Kidney 293T (HEK-293T) cells, ovarian cancer cell lines CaOV3 and SKOV3 were cultured in DMEM containing 10\% FBS, $100 \mu \mathrm{g} / \mathrm{ml}$ streptomycin (Life Technologies, Rockville, MD, USA), 100 U/ml penicillin (Life Technologies), and 0.03\% L-glutamine (SigmaAldrich, St. Louis, MO, USA). TOV-112D and TOV-21G cells were cultured in RPMI-1640 containing 15\% FBS, $100 \mu \mathrm{g} / \mathrm{ml}$ streptomycin, $100 \mathrm{U} / \mathrm{ml}$ penicillin and $0.03 \%$ L-glutamine. OVCAR3 cells were cultured in RPMI-1640 containing $20 \% \mathrm{FBS}, 10 \mu \mathrm{g} / \mathrm{ml}$ bovine insulin, $100 \mu \mathrm{g} / \mathrm{ml}$ streptomycin, $100 \mathrm{U} / \mathrm{ml}$ penicillin and $0.03 \% \mathrm{~L}$-glutamine. $\mathrm{CHO}$ cells were cultured in F-12K containing $10 \%$ FBS, $100 \mu \mathrm{g} / \mathrm{ml}$ streptomycin, $100 \mathrm{U} / \mathrm{ml}$ penicillin and $0.03 \%$ L-glutamine.

MTT colormetric assay. OVCAR3 cells at logarithmic growth phase were seeded in a 96-well plate and incubated at $37^{\circ} \mathrm{C}$ for $24 \mathrm{~h}$, and different dosage of mangiferin $(12.5$, 25,50 and $100 \mu \mathrm{g} / \mathrm{ml}$ ) were added and incubated for 12, 24, 36 and $48 \mathrm{~h}$, respectively. MTT [0.05 $\mathrm{mg}(10 \mu \mathrm{lof} 5 \mathrm{mg} / \mathrm{ml})]$ was added to each well and incubated at $37^{\circ} \mathrm{C}$ for $4 \mathrm{~h}$, and then medium was removed and shaked thoroughly for $1 \mathrm{~h}$. Finally, termination buffer was added into each well. The absorbance at $570 \mathrm{~nm}$ was measured with a spectrophotometer (Model 3550 Microplate Reader, Bio-Rad Laboratories, Hercules, CA, USA). Cell viability (\%) $=[\mathrm{OD} 570 \mathrm{~nm}(\mathrm{drug}) /$ OD $570 \mathrm{~nm}$ (control)] x100\%.

Cell morphology observation. OVCAR3 cells were seeded into a 6 -well culture plate at a density of $4 \times 10^{5}$ cells/well and cultured for $24 \mathrm{~h}$. Control groups were treated with $0.05 \%$ DMSO, and mangiferin groups were treated with $25 \mu \mathrm{g} / \mathrm{ml}$ mangiferin. Hoechst 33342 staining was applied to further detect viable cells. In brief, cells were fixed with $4 \%$ PFA for $30 \mathrm{~min}$ at room temperature after $48 \mathrm{~h}$ incubation with either mangiferin or $0.05 \%$ DMSO, and then cells were washed twice with PBS. Hoechst $33342(5 \mu \mathrm{g} / \mathrm{ml})$ was added and stained for $15 \mathrm{~min}$, and then the cells were washed and analyzed immediately with a fluorescence microscope (Olympus, Tokyo, Japan). All experiments were carried out in triplicate. Experiments were repeated three times, and data are representative of replicate experiments.

Annexin V-FITC/PI flow cytometry. To study the effects of mangiferin on cell apoptosis, OVCAR3 cells were treated with $25 \mu \mathrm{g} / \mathrm{ml}$ mangiferin for $24 \mathrm{~h}$. Detached and adherent cells were then collected and labeled for $15 \mathrm{~min}$ at room temperature with Annexin V-FITC $(1 \mu \mathrm{g} / \mathrm{ml})$ and prodidium iodide (PI, $40 \mu \mathrm{g} / \mathrm{ml}$ ) after washing away unbound fluorescent dye, cells were immediately analyzed on a FACS Aria II cytometer (Becton Dickinson, Franklin Lakes, NJ, USA). Cells (1x10 $)$ were measured for each sample. All experiments were carried 
out in triplicate. Experiments were repeated three times, and data are representative of replicate experiments.

Caspase-3 activity and mitochondrial membrane potential assay. Mangiferin-induced apoptosis of OVCAR3 cells was also assessed by measuring the activity of caspase-3. OVCAR3 cells were seeded into a 6-well culture plate at a density of $4 \times 10^{5}$ cells/well for $16 \mathrm{~h}$ incubation. Subsequently, cells were treated with $25 \mu \mathrm{g} / \mathrm{ml}$ mangiferin for $0,12,24,36,48 \mathrm{~h}$. Caspase- 3 activity was measured by using a caspase- 3 activity kit (Beyotime Institute of Biotechnology, Haimen, China). In brief, cells were lysed, the supernatant was collected, quantified, and incubated with the caspase-3-specific color substrate Ac-DEVD-pNA. Caspase-3 activity was determined by measuring optical density at OD400 $\mathrm{nm}$.

Mitochondrial membrane potential was measured by fluorescent dye rhodamine-123. After treatment with $25 \mu \mathrm{g} / \mathrm{ml}$ mangiferin for $12,24,36$ and $48 \mathrm{~h}$, cells were collected and suspended in $1 \mathrm{ml}$ of PBS containing $1 \mu \mathrm{g} / \mathrm{ml}$ rhodamine- 123 and incubated at $37^{\circ} \mathrm{C}$ for $15 \mathrm{~min}$. The fluorescence intensity of the cells was analyzed on a FACS Aria II cytometer (Becton Dickinson). All experiments were carried out in triplicate. Experiments were repeated three times, and data are representative of replicate experiments.

Western blot analysis. OVCAR3 cells were treated with 0 , $12.5,25,50$ and $100 \mu \mathrm{g} / \mathrm{ml}$ mangiferin for $24 \mathrm{~h}$, respectively, and then both adherent and floating cells were collected. The cell pellets were resuspended with lysis buffer and lysed at $4^{\circ} \mathrm{C}$ for $15 \mathrm{~min}$, and the lysis buffer consisted of $50 \mathrm{mmol} / 1 \mathrm{HEPES}$ (pH 7.4), 1\% Triton X-100, $2 \mathrm{mmol} / 1$ sodium orthovanada, $100 \mathrm{mmol} / 1$ sodium fluoride, $1 \mathrm{mmol} / 1$ edetic acid, $1 \mathrm{mmol} / 1$ PMSF, $10 \mathrm{mg} / 1$ aprotinin and $10 \mathrm{mg} / \mathrm{l}$ leupeptin. After $12,000 \times \mathrm{g}$ centrifugation for $15 \mathrm{~min}$, the protein content of supernatant was determined by Bradford protein assay (cat. no. P0006, Beyotime, Suzhou, China). Equal amounts of the total protein were separated by $4-12 \%$ NuPAGE Bis-Tris gels (cat. no. NP0327BOX, Life Technologies, Carlsbad, CA, USA) and transferred to PVDF membranes (cat. no. ISEQ00010, Millipore, Bedford, MA, USA), the membranes were soaked in blocking buffer (5\% BSA, cat. no. V900933, Sigma-Aldrich Chemicals). Then proteins were detected using primary and secondary antibodies and visualized with ECL (cat. no. 345818 , Millipore). Experiments were repeated three times, and data are representative of replicate experiments.

Lentivirus preparation and transduction. The PCR product of the Notch3 intracellular domain (NICD) was cloned into pTY linkers. Third-generation vectors were used in this experiment. NICD lentiviral vector were transient transfected into HEK-293T cells. Briefly, HEK-293T cells were co-transfected with appropriate amounts of vector plasmids, including helper construct, envelope plasmid, tat plasmid and pTY linker containing NICD. The viruses were collected, concentrated, and $1 \times 10^{6}$ lentiviral particles were transduced to OVCAR3 cells in the presence of $5 \mu \mathrm{g} / \mathrm{ml}$ Polybrene (cat. no. sc-134220, Santa Cruz Biotechnology).

Acute toxicity testing. Acute toxicity testing was performed to determine median lethal dosing $\left(\mathrm{LD}_{50}\right)$ of mangiferin. After
$16 \mathrm{~h}$ fasting, BALB/c mice were randomly divided into 6 groups $(\mathrm{n}=10)$. Graded doses of mangiferin $(10,20,50,100,200$, and $500 \mathrm{mg} / \mathrm{kg}$ ) were separately administered intraperitoneally to the mice. All mice were allowed free access to food and water, and then mortality in each group was assessed after 24, 48 and $72 \mathrm{~h}$ administration of mangiferin. Percentage mortality in each group was calculated and plotted against $\log _{10}$ of mangiferin dose. A regression line was fitted by the method of least squares, and $\mathrm{LD}_{50}$ values were calculated. Animal handling was in accordance with the ethics committee of the Sichuan Academy of Medical Science and Sichuan Provincial People's Hospital, and all animals were kept in $12 \mathrm{~h}$ light/dark cycle with free access to water and food, which is in consistent with IVC requirement in Sichuan Academy of Medical Science and Sichuan Provincial People's Hospital.

Tumor xenograft study. The in vivo efficacy of mangiferin was studied in xenograft models. In brief, to initiate tumor xenografts, $5 \times 10^{6}$ OVCAR3 cells were injected into BALB/c nude female mice. After implantation, tumors were allowed to grow to a size of $100-550 \mathrm{~mm}^{3}$ before starting daily treatment. Mice were randomly divided into five groups: 1) Blank control group: mice intraperitoneally administered PBS after tumor formation by OVCAR3 cells; 2) High dose mangiferin group: mice intraperitoneally administered $100 \mathrm{mg} / \mathrm{kg}$ mangiferin after tumor formation by OVCAR3 cells; 3) Medium dose mangiferin group: mice intraperitoneally administered $50 \mathrm{mg} / \mathrm{kg}$ mangiferin after tumor formation by OVCAR3 cells; 4) Low dose mangiferin group: mice intraperitoneally administered $10 \mathrm{mg} / \mathrm{kg}$ mangiferin after tumor formation by OVCAR3 cells; 5) Combined therapy group: mice intraperitoneally administered both cisplatin $(10 \mathrm{mg} / \mathrm{kg})$ and mangiferin $(50 \mathrm{mg} / \mathrm{kg}$ ) after tumor formation by OVCAR3 cells.

The administration of mangiferin lasted for another two weeks. Before and after the mangiferin treatment, the body weight of the mice was measured daily then, 5 mice in each group were sacrificed, and 5 mice in each group were raised for survival assay. For the sacrificed mice, the subcutaneous tumors were peeled off and weighed. The volume of tumors was determined in three dimensions with vernier calipers according to the formula: Tvol $=$ length $\mathrm{x}$ width $\mathrm{x}$ depth $\mathrm{x} 0.5$, and then relative tumor volume was calculated as relative increase or decrease in mean tumor volume from initiation of treatment (V0) up to value at a given time $(\mathrm{Vt})$ and $\mathrm{RTV}=\mathrm{Vt} / \mathrm{VO}$. Inhibitory rate of tumor volume $=($ Vcontrol x Vt $) /$ Vcontrol x100\%. After 14 days treatment, mice were sacrificed by cervical dislocation, and subcutaneous tumor masses were determined. Inhibitory level of tumor weight $=$ Wcontrol $-\mathrm{Wt}$ ) $/$ Wcontrol $\times 100 \%$.

Statistical analysis of the data. All data were expressed as mean values \pm SEM from at least three independent experiments. Statistical significance was determined by two-way ANOVA and Student's t-test. Experiments were repeated three times, and data are representative of replicate experiments.

\section{Results}

Mangiferin inhibits viability of OVCAR3 cells. Based on our previous study on mangiferin (30), we hypothesized that mangiferin might inhibit the viability of ovarian cancer 

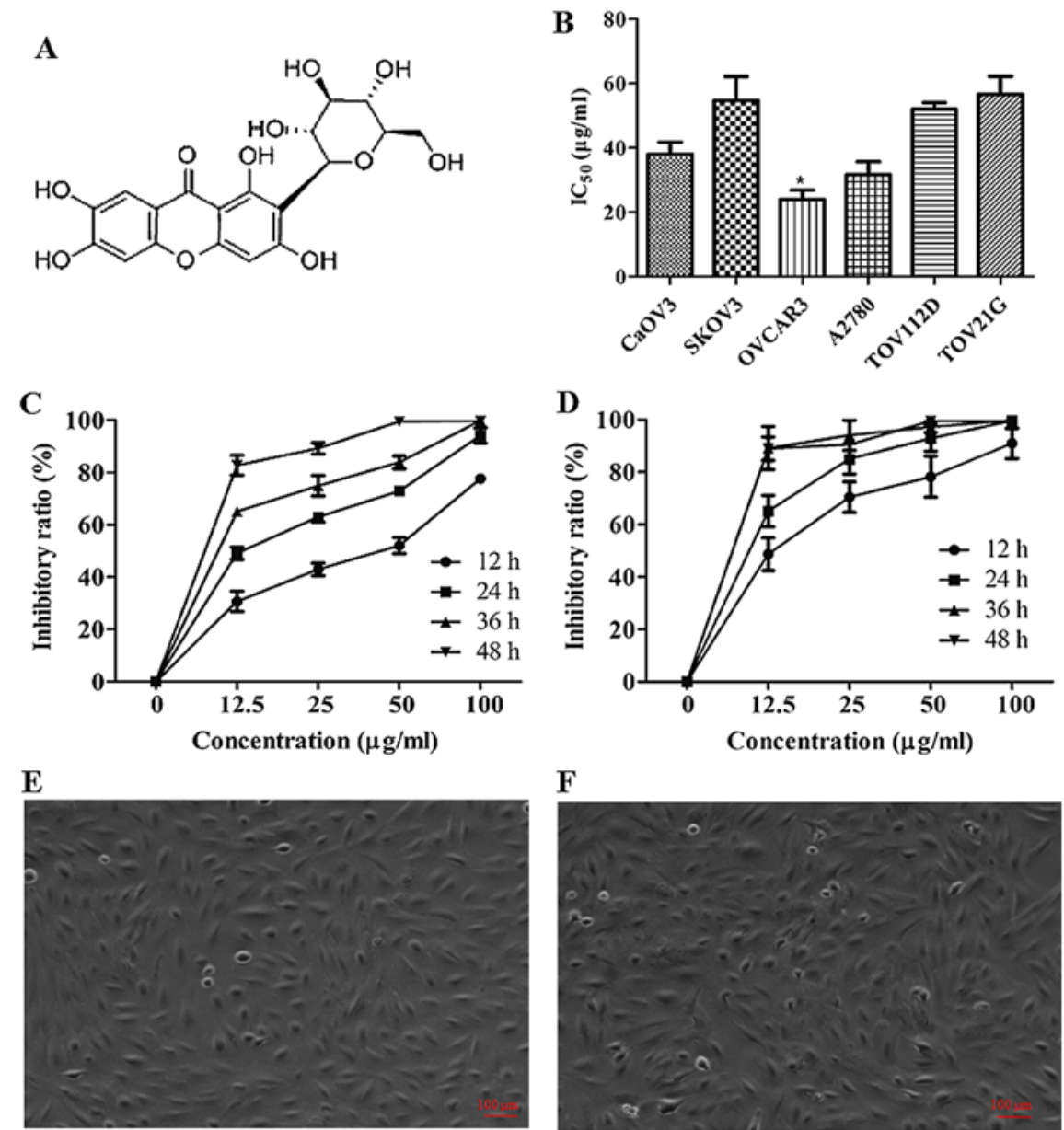

Figure 1. Mangiferin inhibits cell viability and increases sensitivity to cisplatin. (A) Chemical structure of mangiferin. (B) The IC $\mathrm{I}_{50}$ values of human ovarian adenocarcinoma OVCAR3 cells, CaOV3 cells, SKOV3 cells, A2780 cells, endometrioid carcinoma TOV-112D cells, and clear cell carcinoma TOV-21G cells . ${ }^{*} \mathrm{P}<0.05$ by one-way ANOVA. (C) Time course and dose-dependent assay of OVCAR3 cells. $\mathrm{P}<0.05$ by two-way ANOVA. (D) Inhibitory ratio of combined treatment with both mangiferin and cisplatin. Representative phase contrast images of CHO cells treated with $100 \mu \mathrm{g} / \mathrm{ml}$ for $24 \mathrm{~h}(\mathrm{E})$ and $48 \mathrm{~h}(\mathrm{~F})$. P $<0.05$ by two-way ANOVA. Data are means \pm SEM from 3 independent experiments.

cells. Therefore, to substantiate our hypothesis and to explore the inhibitory role of mangiferin in ovarian cancer cells, we performed MTT assay on ovarian adenocarcinoma cell lines (CaOV3, SKOV3, OVCAR3 and A2780), endometrioid carcinoma cell line TOV-112D and clear cell carcinoma cell line TOV-21G (Fig. 1B). The $\mathrm{IC}_{50}$ values were $38.14 \mu \mathrm{g} / \mathrm{ml}$ for $\mathrm{CaOV} 3,57.67 \mu \mathrm{g} / \mathrm{ml}$ for SKOV3, $31.67 \mu \mathrm{g} / \mathrm{ml}$ for A2780, $24.13 \mu \mathrm{g} / \mathrm{ml}$ for OVCAR3, 53.65 $\mu \mathrm{g} / \mathrm{ml}$ for TOV-112D and $56.69 \mu \mathrm{g} / \mathrm{ml}$ for TOV-21G. These data strongly suggested that mangiferin could inhibit the viability of ovarian carcinoma cell lines, and OVCAR3 cells were most sensitive to mangiferin treatment. To ascertain whether mangiferin treatment was dose- and time-dependent, OVCAR3 cells were treated with different dosage of mangiferin $(0,12.5,25,50,100 \mu \mathrm{g} / \mathrm{ml})$ for 12, 24, 36, and $48 \mathrm{~h}$ (Fig. 1C). As predicted, accompanied with increased dosage and extended treatment, the inhibitory ratio increased, suggesting that mangiferin inhibited the proliferation of OVCAR3 cells in a dose- and time-dependent manner. In addition, it has been widely acknowledged that the standard first-line treatment for advanced stage ovarian carcinoma is the combined chemotherapy of platinum based drugs as cisplatin coupled with paclitaxel (31). However, most patients will relapse due to drug resistance. Therefore to validate whether mangiferin treatment could enhance the sensitivity of OVCAR3 cells to cisplatin, we evaluated the inhibitory rates of combined therapy of both mangiferin and cisplatin. Simultaneously with $1 \mu \mathrm{g} / \mathrm{ml}$ cisplatin, different dosages of mangiferin $(0,12.5,25,50$ and $100 \mu \mathrm{g} / \mathrm{ml})$ were added into the culture medium of OVCAR3 cells (Fig. 1D). As expected, increased inhibitory ratios were observed, suggesting that mangiferin treatment could improve the sensitivity of ovarian carcinoma cells to cisplatin in dose- and time-dependent manner. However, $100 \mu \mathrm{g} / \mathrm{ml}$ mangiferin did not result in apparent apoptotic morphology in non-cancerous Chinese Hamster Ovary (CHO) cells after 24 or $48 \mathrm{~h}$ treatment (Fig. 1E and $\mathrm{F}$ ). These results suggested that mangiferin might selectively induce OVCAR3 cells apoptosis but could not trigger apoptosis of normal ovary cells.

Mangiferin induces apoptosis. To address whether mangiferin could induce apoptosis, we observed the cell morphology under phase contrast microscopy (Fig. 2A). It was obvious that cells treated with $25 \mu \mathrm{g} / \mathrm{ml}$ mangiferin for $48 \mathrm{~h}$ showed shrinkage of cytoplasm and nucleus, membrane blebbing, and shattering, which are typical in apoptotic morphology. Furthermore, less viable cells were observed in the cisplatin plus mangiferin 
A

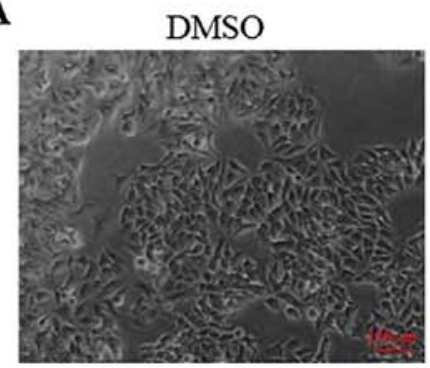

B

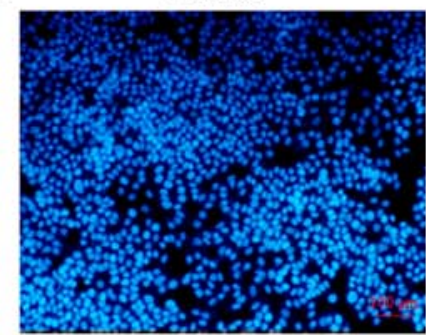

C

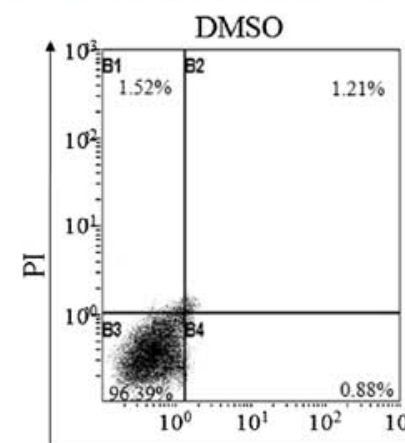

Mangiferin

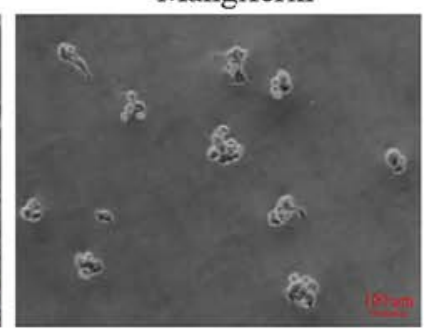

Mangiferin
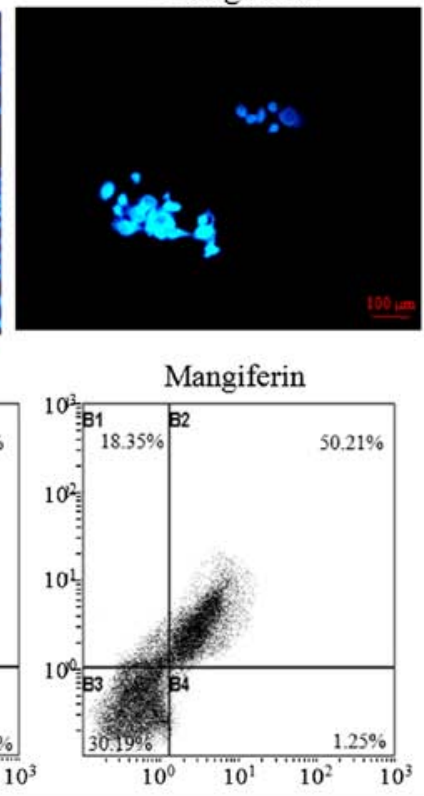
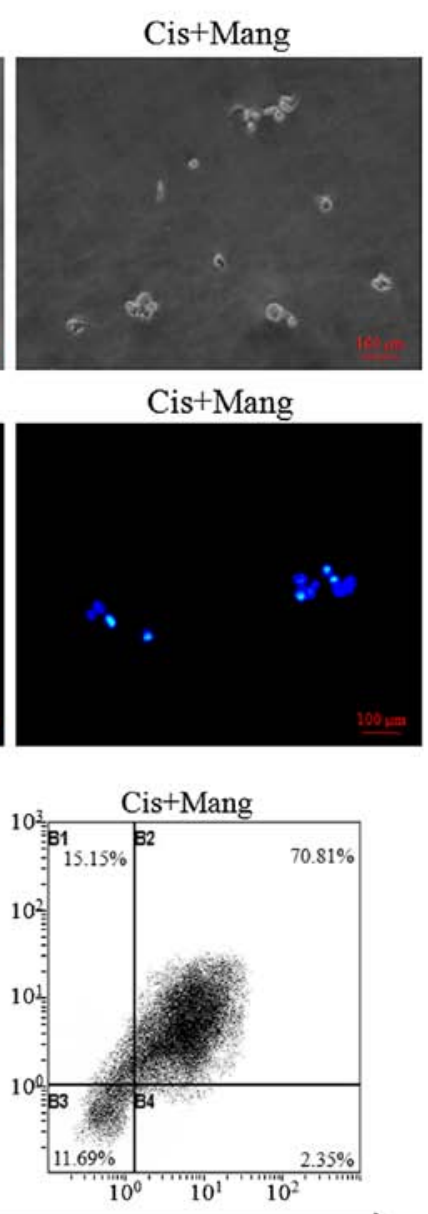

Annexin V

D

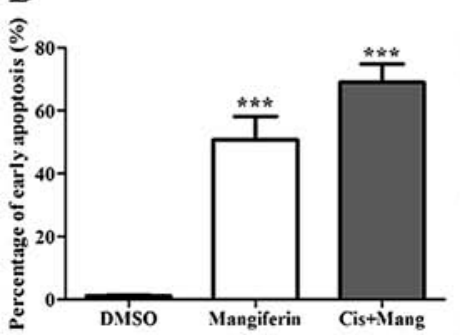

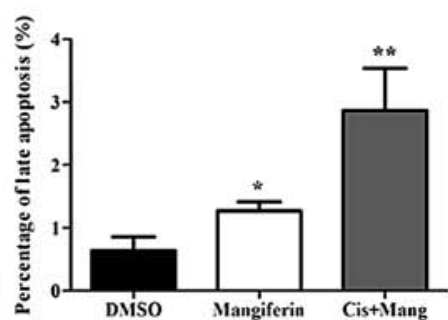

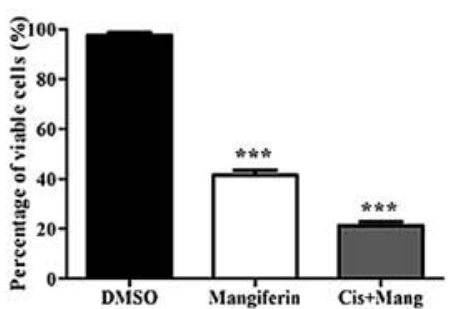

Figure 2. Mangiferin induces apoptosis. Representative phase contrast images (A) and fluorescent images (B) of OVCAR3 cells treated with DMSO (left), mangiferin (middle) and mangiferin plus cisplatin (right). Images are x 200 magnifications with scale bar representing $100 \mu \mathrm{m}$. (C) Flow cytometry analysis of apoptosis by Annexin V and PI double staining. (D) Statistics of early apoptotic cells, late apoptotic cells and viable cells. ${ }^{*} \mathrm{P}<0.05,{ }^{* *} \mathrm{P}<0.01$ and ${ }^{* * * *} \mathrm{P}<0.001$ vs. DMSO control group by Student's t-test. Data are means \pm SEM from 3 independent experiments.

treated group. To substantiate our observations, we preformed Hoechst 33342 staining, and found that the remaining cells in mangiferin treated group showed condensed nuclei, indicating those cells were underging apoptosis (Fig. 2B). In order to determine the apoptotic percentages of each group, cells were treated with $25 \mu \mathrm{g} / \mathrm{ml}$ mangiferin for $24 \mathrm{~h}$, and then sorted by flow cytometry. As shown in Fig. $2 \mathrm{C}$, there were more early apoptotic (Annexin $\mathrm{V}^{+} / \mathrm{PI}^{-}$) cells and late apoptotic cells (Annexin $\mathrm{V}^{+} / \mathrm{PI}^{+}$) in mangiferin treated group compared to those of the controls. Statistics on the early apoptotic cells, late apoptotic cells and viable cells are in accordance further demonstrating that mangiferin induced apoptosis of OVCAR3 cells and increased the sensitivity of OVCAR3 cells to cisplatin treatment (Fig. 2D). Taken together, based on the qualitative and quantitative analysis of the apoptotic events, mangiferin was able to induce apoptosis in ovarian carcinoma OVCAR3 cells.

Mangiferin induces apoptosis via caspase pathway. To unravel the mechanism of mangiferin-induced apoptosis, and to determine whether it relied on the caspase pathway, a series of western blotting were performed. Accumulating evidence revealed that during apoptosis, cytochrome $\mathrm{c}$ is released from mitochondria to cytosoplasm (32). We, therefore, assessed the cytosol and mitochondria cytochrome $\mathrm{c}$, and found that mangiferin treatment could promote the translocation of cytochrome $\mathrm{c}$ from mitochondria. Furthermore, activation of caspase plays a central role in apoptosis, and caspase- 3 serves 

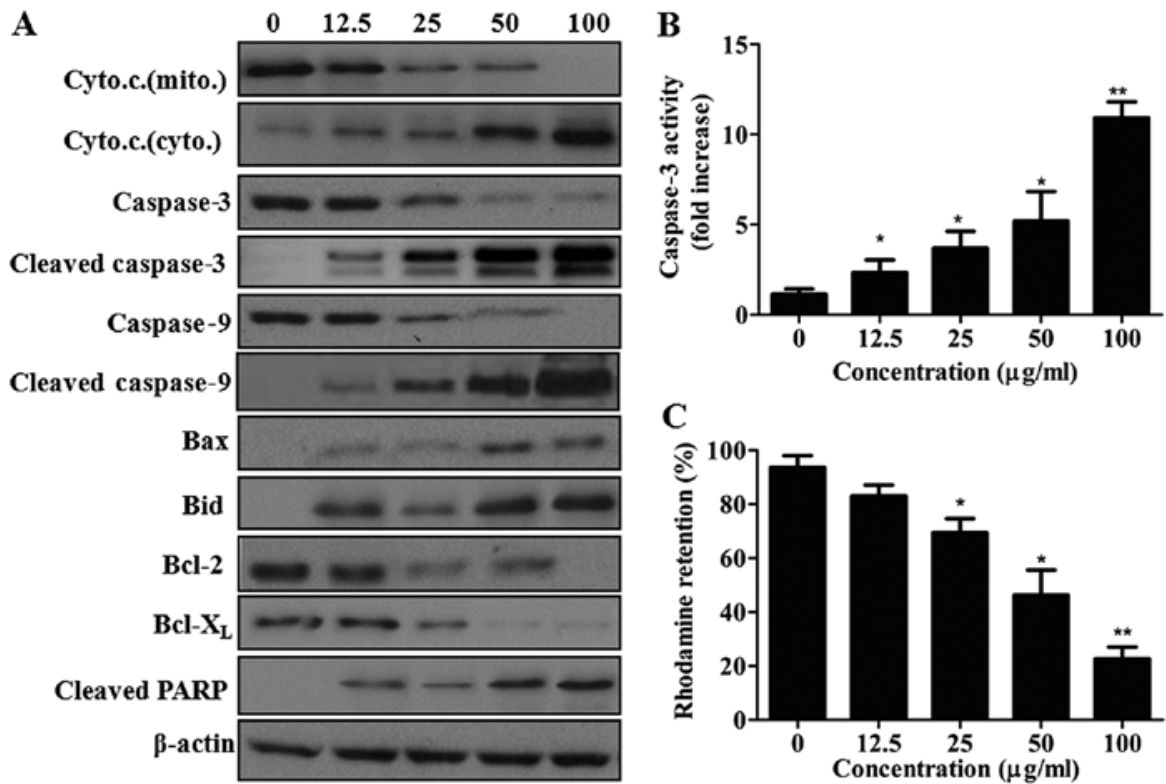

Figure 3. Mangiferin induces caspase-3-dependent apoptosis. (A) Representative western blot images of key proteins in caspase pathway. (B) Caspase-3 acitivities of mangiferin treated cells were dose-dependent. (C) Rhodamine retentions were analyzed. Data are means \pm SEM from 3 independent experiments. ${ }^{*} \mathrm{P}<0.05$ and ${ }^{* *} \mathrm{P}<0.01$ vs. control (0 M mangiferin).
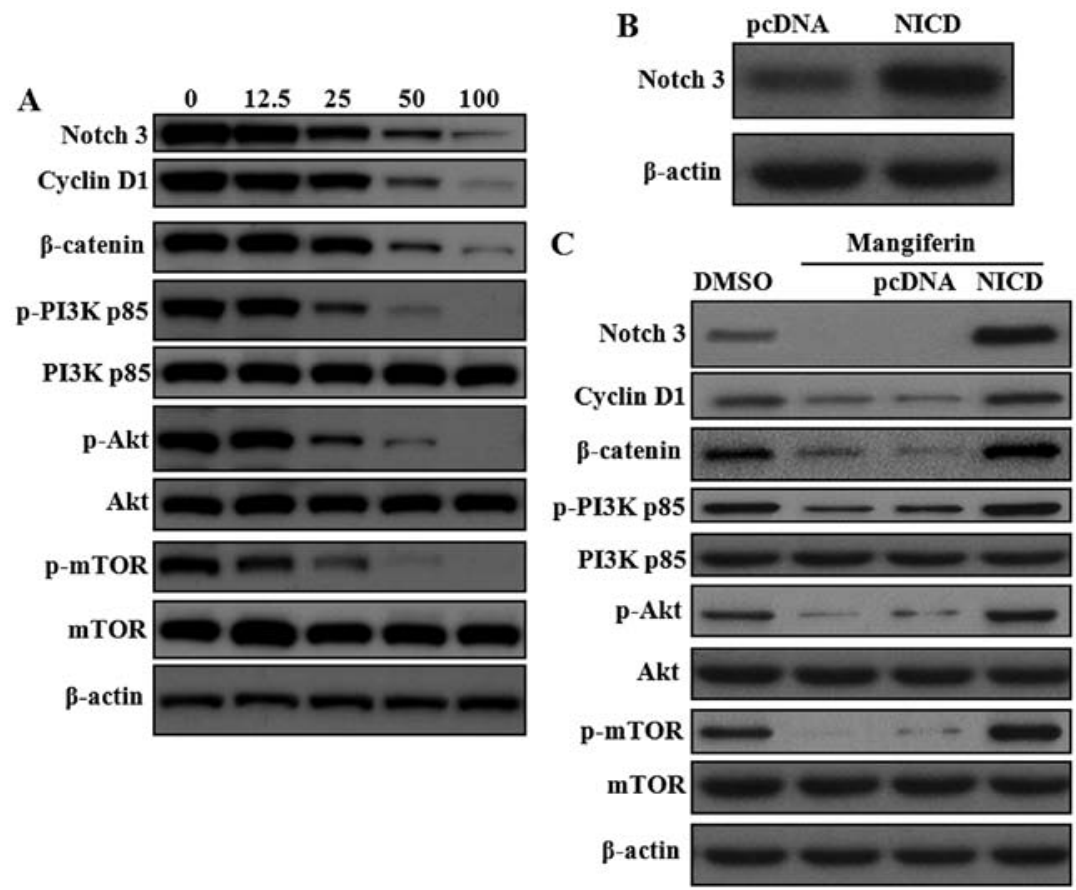

Figure 4. Mangiferin regulates Notch3, Wnt and Akt pathway. (A) Western blot images of Notch3, cyclin D1, $\beta$-catenin, and PI3K/Akt/mTOR signaling pathway. (B) Overexpression of NICD (Notch3 intracellular domain). (C) Western blot images of cells treated with both mangiferin and NICD lentivirus. Images are representative from 3 independent experiments.

as the convergence point of different apoptotic signaling pathway. As shown in Fig. 3A, caspase-3 and -9 were activated upon mangiferin treatment with increased cleaved caspase-3 and -9. As Bid induces conformational change of Bax, and Bax induces the release of cytochrome $\mathrm{c}$ from mitochondria during apoptosis, we found mangiferin treated cells had higher expression level of Bax and Bid compared with that of the control, suggesting more apoptotic events mediated by mangiferin. However, as the protein Bcl-2 interferes with the activation of caspases by preventing the release of cytochrome c, cells treated with mangiferin showed a comparatively lower expression level of Bcl-2. Moreover, decreased Bcl- $\mathrm{X}_{\mathrm{L}}$ and increased PARP cleavage were found in mangiferin treated cells. To further validate that caspase pathway was involved in mangiferin-induced apoptosis, we analyzed the caspase- 3 activity and determined the integrity of mitochondria membrane. As expected, caspase activity increased in accordance with the dosage of mangiferin 
A

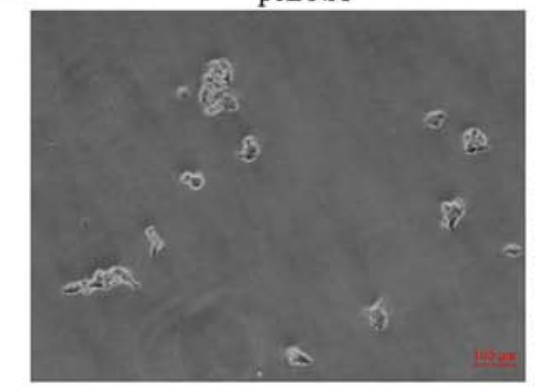

B

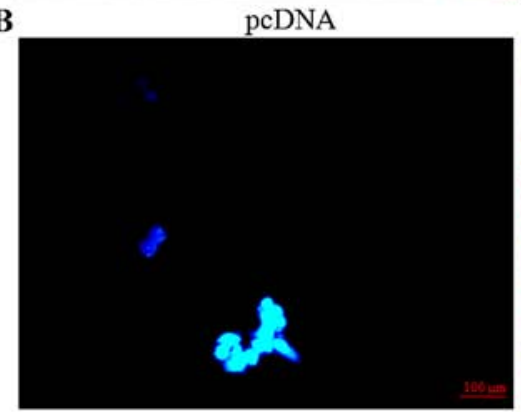

C

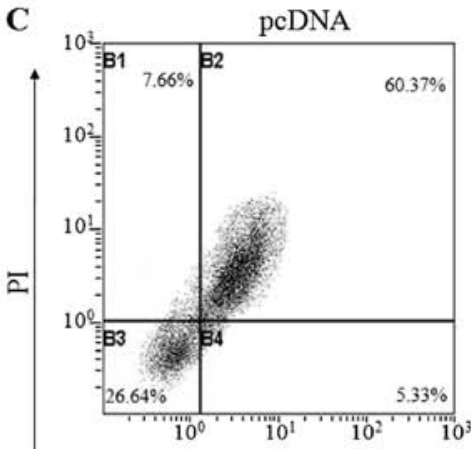

NICD

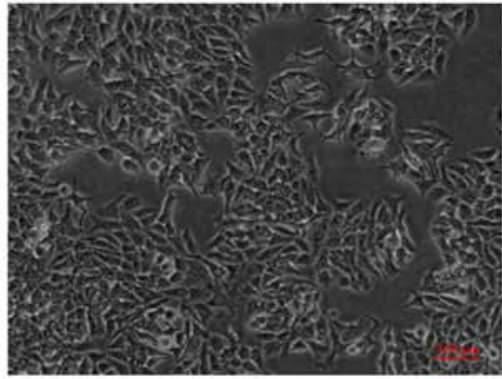

NICD

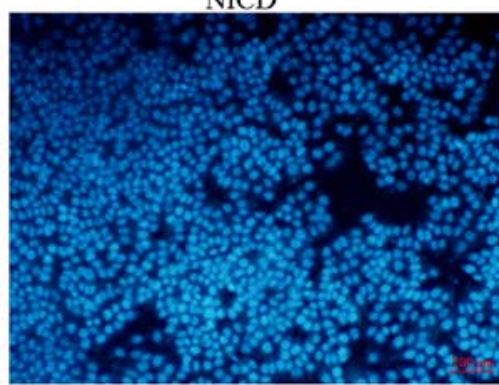

NICD

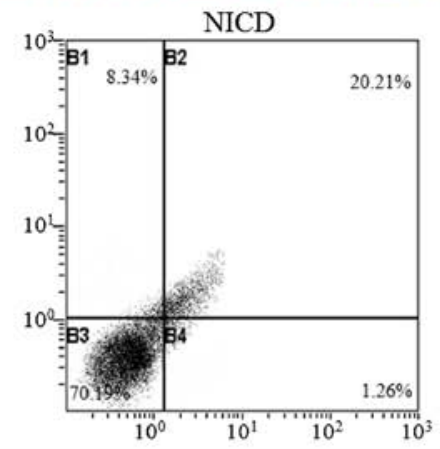

Annexin V

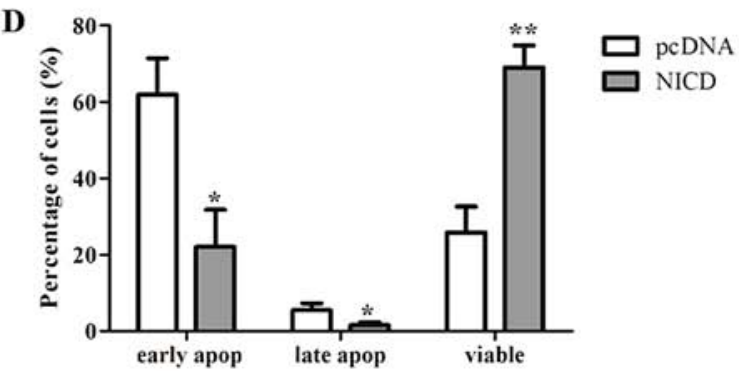

Figure 5. Notch3 overexpression abrogates the apoptosis-inducing effect of mangiferin. Representative phase contrast images (A) and fluorescent images (B) of OVCAR3 cells treated with mangiferin (left) and mangiferin plus NICD lentivirus (right). Images are x 200 magnifications with scale bar representing $100 \mu \mathrm{m}$ (C) Flow cytometry analysis of apoptosis by Annexin V and PI double staining. (D) Statistics of early apoptotic cells, late apoptotic cells and viable cells. ${ }^{*} \mathrm{P}<0.05$ and ${ }^{* *} \mathrm{P}<0.01$ vs. pcDNA transfected OVCAR3 cells by Student's $t$-test. Data are means \pm SEM from 3 independent experiments.

(Fig. 3B). Whereas, mitochondria membrane integrity was decreased with the increased dosage, suggesting that mangiferin stimulated the release of cytochrome c (Fig. 3C).

Mangiferin induces apoptosis through the inhibition of Notch3. As discussed above, because Notch signaling pathway plays a crucial role in the pathogenesis and chemoresistance of ovarian cancer, we evaluated whether mangiferin could inhibit the expression of Notch1 and Notch3. As shown in Fig. 4A, mangiferin could reduce protein levels of Notch3, but has no effect on Notch1 (data not shown). Besides, as amplification and overexpression of cyclin D1 have been found in several human malignancies (33), the expression levels of cyclin D1 and $\beta$-catenin were determined and were also found to be inhibited by mangiferin. Previous report clearly showed crosstalk between Notch and PI3K/Akt (34), therefore, we examined whether mangiferin has any inhibitory effect on PI3K/Akt. As expected, decreased phosphorylation of PI3K p85 (Y607), Akt (S473) and mTOR (S2448) were found in mangiferin treated cells. To further substantiate the inhibitory role of mangiferin on Notch signaling pathway, Notch3 intracellular domain (NICD) were overexpressed in OVCAR3 cells by lentivirus infection (Fig. 4B). Then we found that mangiferin-induced inhibition of cyclin D1, $\beta$-catenin and PI3K/Akt/mTOR could 
A
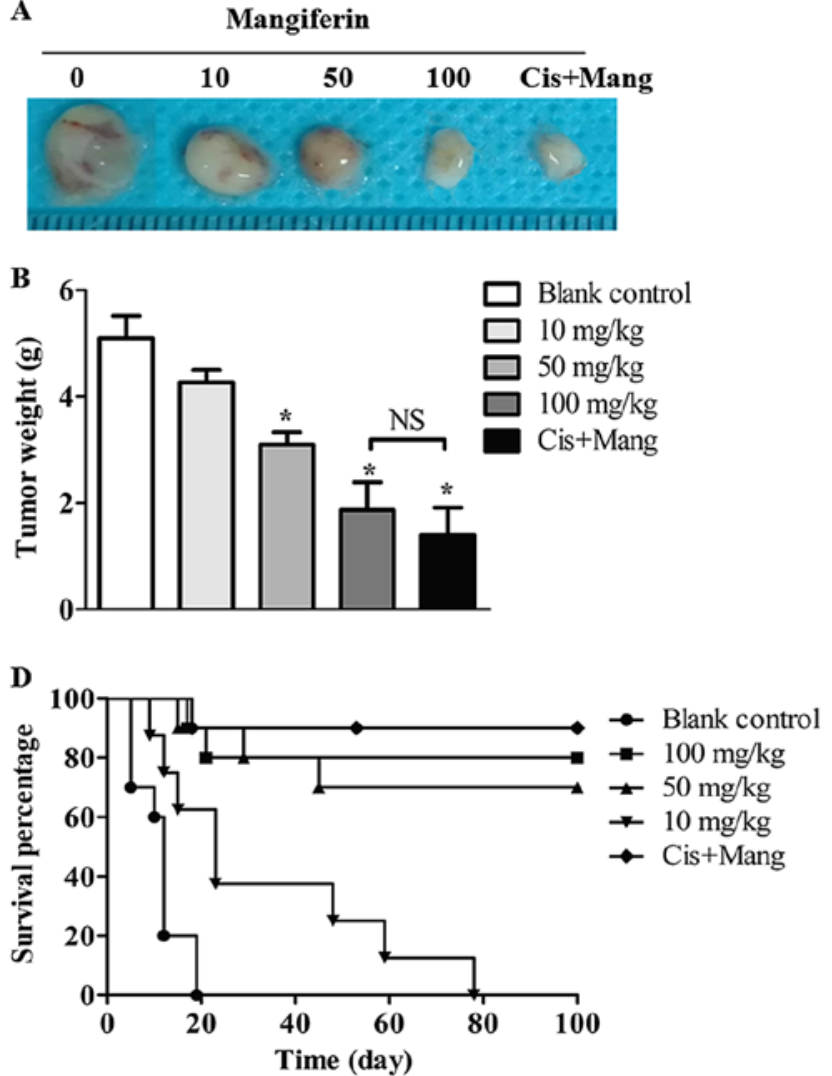

C
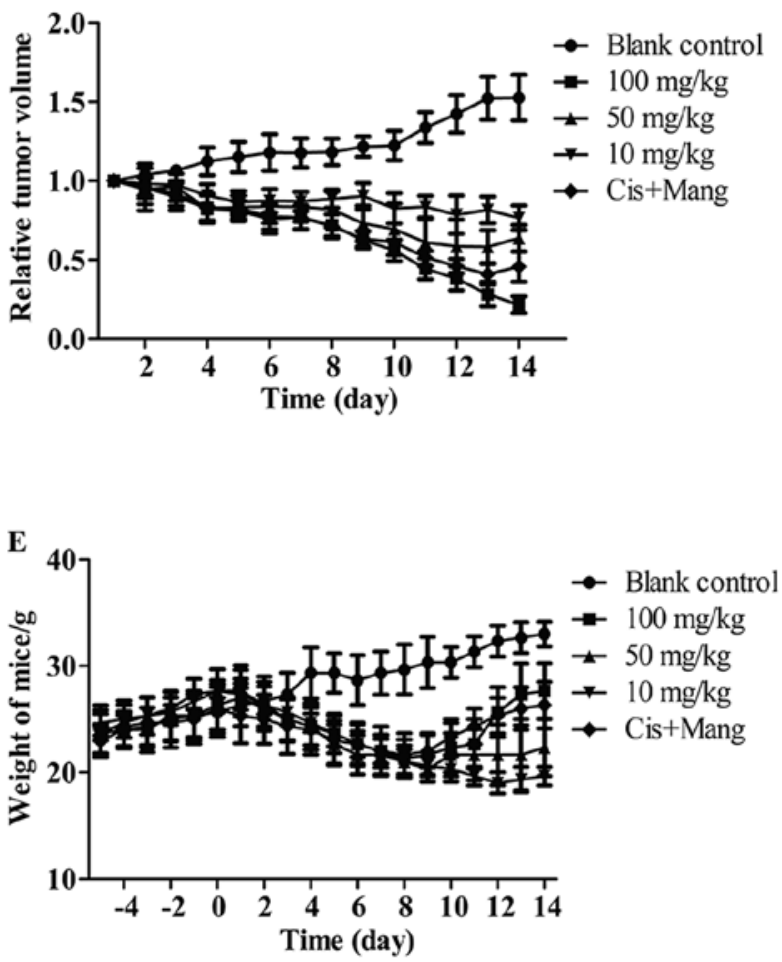

Figure 6. Mangiferin inhibits OVCAR3 cell xenograft tumor growth. (A) Representative image of xenograft tumors. (B) Tumor weights of each group. (C) Relative tumor volume of each group ( $\mathrm{n}=10, \mathrm{P}<0.05$ by two-way ANOVA). (D) Survival curve of OVCAR3 cell xenograft mice ( $\mathrm{n}=10$, $\mathrm{P}<0.05$ by two-way ANOVA). (E) Weight changes of OVCAR3 cell xenograft mice ( $\mathrm{n}=10, \mathrm{P}<0.05$ by two-way ANOVA). Cis + Mang represent combined therapy of cisplatin plus mangiferin.

be partially abrogated by Notch3 overexpression, highlighting the critical role of Notch3 in the anti-neoplastic effect of mangiferin (Fig. 4C).

Further studies on cell morphology revealed that Notch3 overexpression played a protective role from apoptosis for cells treated with mangiferin. Cell treated with mangiferin showed shrinking and bubbling compared with cells treated with both mangiferin and Notch3 (NICD) overexpressed lentivirus (Fig. 5A). Besides, fluorescent staining revealed that cells showed more condensed nuclei after mangiferin treatment. In contrast, more viable cells were found in mangiferin treated Notch3 overexpressed cells (Fig. 5B). Quantification of apoptotic cells by flow cytometry clearly showed that overexpression of Notch3 rescued the cells from apoptosis (Fig. 5C and D).

Mangiferin inhibits tumor growth in vivo. Based on our in vitro results, we decided to evaluate the anti-neoplastic properties of mangiferin in an in vivo tumor xenograft model system. Therefore, OVCAR3 cells were xenografted into nude mice, and then examined the growth rates of these tumors with or without mangiferin treatment. On the basis of caliper measurements (Fig. 6A), after 14 days of treatment, with the increase dose of mangiferin, the xenograft tumor volume decreased significantly compared to that of the blank control group. Similarly, mangiferin plus cisplatin treated mice showed reduced xenograft tumor volume, suggesting mangiferin could increase the sensitivity of ovarian cells to cisplatin. Moreover, tumor weights were also decreased after mangiferin therapy (Fig. 6B). In addition, calculation of the relative tumor volume demonstrated that mangiferin treatment could greatly inhibit tumor growth (Fig. 6C). Furthermore, judged from the survival curve, mangiferin could remarkably prolong the life span of OVCAR3 cell xenograft mice compared with blank control group (Fig. 6D). Therefore, accompanied with decreased tumor size, body weights of mice receiving mangiferin treatment, showed gradual but remarkable recovery after mangiferin treatment (Fig. 6E). In summary, our in vivo data clearly indicated that mangiferin could inhibit tumor growth, supporting the potential use of mangiferin as a chemotherapeutic agent in ovarian cancer.

\section{Discussion}

Based on recently published statistics ovarian cancer is the fifth leading cause of cancer death in women (1). Partially due to the nonspecific symptom, most patients are diagnosed at an advanced stage, which ultimately lead to the high mortality of this disease. Most patients are initially sensitive to surgery and platinum based therapy, but the majority will relapse and become drug resistant. Therefore, it is well established that the development of effective therapeutic agents for ovarian cancer is of great importance. Given our observation of 
mangiferin on human lung carcinoma, we hypothesized that mangiferin could induce apoptosis in ovarian cancer. In the current study, we found that mangiferin remarkably inhibited the viability of ovarian carcinoma cells, and markedly increased tumor sensitivity to cisplatin both in vitro and in vivo. We further showed that caspase-dependent apoptosis pathway was activated by mangiferin. Of note, we observed that Notch signaling pathway was involved in mangiferininduced apoptosis, and crosstalk between Notch and Wnt, PI3K/Akt was also regulated by mangiferin. In addition, cell morphology observation and apoptosis assays by Annexin V and PI revealed that Notch3 (NICD) overexpression blocked the inhibitory effect of mangiferin. Furthermore, data collected from tumor growth and survival curve in animal models indicated a strong response of xenograft tumors to mangiferin treatment.

Previous studies on mangiferin revealed the anti-cancer effects of mangiferin by inhibiting tumor necrosis factor (TNF)-induced activation of NF- $\mathrm{B}$ (35). Besides, mangiferin treatment enhanced the detoxification activity of enzymes, including glutathione transferase, quinone reductase and uridin 5'-diphosphate-glucuronosyl transferase, and reduced DNA damage in lung cancer-bearing animals (36). In addition, mangiferin was reported to inhibit telomerase activity and to induce apoptosis in K562 cells $(8,9)$, and Mangifera indica extract also initiated $\mathrm{G}_{0} / \mathrm{G}_{1}$ phase cell cycle arrest (10). Our previous studies showed that mangiferin induced apoptosis of human lung carcinoma A549 cells by the activation of $\mathrm{NF}-\kappa \mathrm{B}$ and through caspase-dependent pathway. Although, the primary finding from our present study was that mangiferin was able to induce apoptosis of ovarian cancer cells via caspase-dependent pathway, the mechanisms underlying the mangiferin induced apoptosis need to be further explored.

Notch signaling pathway is a highly conserved and strictly regulated playing a critical role in the maintenance of tissue homeostasis by the regulation of proliferation, differentiation and apoptosis in normal tissue. In contrast, recent evidence revealed that the misregulated Notch was tightly correlated with tumorigenesis (37). Therefore, beyond its basic regulatory role of self-renewal and cell-fate determination, aberrantly deregulated Notch is thought to be involved in a wide variety of human malignancies and it is deemed as a therapeutic target in cancer (38). Studies by Rose et al showed that Notch1 was overexpressed in ovarian cancer cell lines and human ovarian cancer clinical samples, and depletion of Notch1 led to the growth inhibition (9). In contrast, blocking the activity of Notch1 contributed to cell growth inhibition and apoptosis in ovarian cancer cells A2780 (39). Therefore, studies on the pytomedicine xanthohumol revealed that xanthohumol induced the growth inhibition by downregulation of Notch1 transcription and protein expression (40). Besides, epigenetic silencing of microRNA-199b-5p was associated with acquired chemoresistance in ovarian cancer via the activation of JAG1-Notch1 signaling, suggesting that Notch1 signaling was correlated with drug resistance (41). Unfortunately, we did not detect significant decrease of Notch1 expression after mangiferin treatment, indicating that mangiferin might selectively inhibit Notch3, and may have no influence on Notch1.
Studies by Park et al showed that Notch3 gene copy number is increased and is correlated with ovarian cancer (8). Noteworthy, our data show that mangiferin exerted its antineoplastic effect by the inhibition of Notch signaling pathway in a dose-dependent manner. Furthermore, Park and his group also found that aberrant expression of Notch3 was related to the recurrence and participated in development of chemoresistance of OVCAR3 cells to carboplatin (42). Studies on the mechanism of chemoresistance revealed that Notch3 might induce epithelial to mesenchymal transition, which led to the carboplatin resistance in ovarian cancer cells (43). Therefore, for advanced stage chemoresistant ovarian cancer, Notch3 could be a potential therapeutic target (17). Herein, our studies strongly support the notion that by targeting Notch3 activation, mangiferin sensitized ovarian cancer cells to cisplatin, which further substantiated that Notch3 is related with chemoresistance. However, given that Notch3 (NICD) overexpression rescued cells from mangiferin-induced apoptosis, the antineoplastic effects of mangiferin in sensitizing ovarian tumors to cisplatin therapy was Notch pathway specific. Moreover, McAuliffe et al found that Notch3 was also activated in ovarian cancer stem cells, and inhibition of Notch will increase the sensitivity of ovarian tumors to platinum therapy (44). Besides, Notch3 ligand Jagged-1 was also involved in the regulation of ovarian tumor growth (45), and its expression was regulated by Notch3 and Wnt/ $\beta$-catenin (46), indicating crosstalk between Notch and Wnt in ovarian cancer. We confirmed that the inhibition of Notch3 by mangiferin interferes with the activation of Wnt/ $\beta$-catenin pathway. Not only crosstalk between Notch and Wnt/ $\beta$-catenin pathway was influenced by mangiferin, but also the PI3K/Akt/mTOR pathway was regulated by mangiferin. Surprisingly, exogenously overexpressed Notch3 abrogated the inhibitory effect of mangiferin on the activation of PI3K/Akt/ mTOR pathway. Besides its apoptosis-inducing effect, these results confirmed and extended our previous findings with the regulatory and chemosensitization function of mangiferin.

To determine whether mangiferin treatment could eradicate tumors, mice bearing established OVCAR 3 tumors $\left(100 \mathrm{~mm}^{3}\right)$ were treated with mangiferin at 10,50 , and $100 \mathrm{mg} / \mathrm{kg} / \mathrm{day}$ for consecutive 14 days. On the basis of caliper measurements, although complete tumor regression did not occur in all mice, the tumors treated with the efficacy dose (50 and $100 \mathrm{mg} / \mathrm{kg} /$ day) did not re-grow during a 100-day observation period after the end of treatment. However, mice treated with only $10 \mathrm{mg} / \mathrm{kg} /$ day mangiferin showed a remarkable longer survival during the initial one month. However, with the retreat of mangiferin, tumors re-grew, which ultimately lead to mortality of the mice. Therefore, as we expected, in the murine models, mangiferin substantially inhibited tumor growth. In future studies, in order to collect more pre-clinical data, we plan to explore the anti-angiogenesis and anti-invasion effect of mangiferin on ovarian cancer cells. Besides, the toxicity and safety of mangiferin should be carefully investigated before its clinical application.

In summary, based on our previous and current research, there is great hope that mangiferin, functioning as a molecularly targeted therapy of Notch3, will offer a new and substantially different drug to the treatment of human cancers. We anticipate that with the gradually clarification of the molecular mechanisms of mangiferin, our work will pave the way in the near 
future for developing mangiferin as a new therapeutic drug by targeting cell apoptosis pathways and enhancing the response to cisplatin treatment for ovarian cancer therapy.

\section{Acknowledgements}

This study was supported by Sichuan Health and Family Planning Commission Funding (16ZD0253), Sichuan National Science Research Funding (2015JY0183), Funding from Sichuan Academy of Medical Science and Sichuan Provincial People's Hospital, and Sichuan Scientific Research Foundation of the Returned Overseas Chinese Scholars for Y.W.

\section{References}

1. Siegel RL, Miller KD and Jemal A: Cancer statistics, 2016. CA Cancer J Clin 66: 7-30, 2016.

2. Choi JH, Wong AS, Huang HF and Leung PC: Gonadotropins and ovarian cancer. Endocr Rev 28: 440-461, 2007.

3. Ozols RF: Systemic therapy for ovarian cancer: Current status and new treatments. Semin Oncol 33 (Suppl 6): S3-S11, 2006.

4. Agarwal R and Kaye SB: Ovarian cancer: Strategies for overcoming resistance to chemotherapy. Nat Rev Cancer 3: 502-516, 2003.

5. Mabuchi S, Kuroda H, Takahashi R and Sasano T: The PI3K/ AKT/mTOR pathway as a therapeutic target in ovarian cancer. Gynecol Oncol 137: 173-179, 2015.

6. Arend RC,Londoño-Joshi AI, Straughn JM Jr and Buchsbaum DJ: The Wnt/ $\beta$-catenin pathway in ovarian cancer: A review. Gynecol Oncol 131: 772-779, 2013

7. Takebe N, Harris PJ, Warren RQ and Ivy SP: Targeting cancer stem cells by inhibiting Wnt, Notch, and Hedgehog pathways. Nat Rev Clin Oncol 8: 97-106, 2011.

8. Park JT, Li M, Nakayama K, Mao TL, Davidson B, Zhang Z, Kurman RJ, Eberhart CG, Shih IeM and Wang TL: Notch3 gene amplification in ovarian cancer. Cancer Res 66: 6312-6318, 2006.

9. Rose SL, Kunnimalaiyaan M, Drenzek J and Seiler N: Notch 1 signaling is active in ovarian cancer. Gynecol Oncol 117: 130-133, 2010.

10. Liao X, Siu MK, Au CW, Wong ES, Chan HY, Ip PP, Ngan HY and Cheung AN: Aberrant activation of hedgehog signaling pathway in ovarian cancers: Effect on prognosis, cell invasion and differentiation. Carcinogenesis 30: 131-140, 2009.

11. Artavanis-Tsakonas S, Rand MD and Lake RJ: Notch signaling: Cell fate control and signal integration in development. Science 284: 770-776, 1999.

12. Dang TP: Notch, apoptosis and cancer. Adv Exp Med Biol 727: 199-209, 2012.

13. Weng AP, Ferrando AA, Lee W, Morris JP IV, Silverman LB, Sanchez-Irizarry C, Blacklow SC, Look AT and Aster JC: Activating mutations of NOTCH1 in human T cell acute lymphoblastic leukemia. Science 306: 269-271, 2004.

14. Westhoff B, Colaluca IN, D'Ario G, Donzelli M, Tosoni D, Volorio S, Pelosi G, Spaggiari L, Mazzarol G, Viale G, et al: Alterations of the Notch pathway in lung cancer. Proc Natl Acad Sci USA 106: 22293-22298, 2009.

15. Stylianou S, Clarke RB and Brennan K: Aberrant activation of notch signaling in human breast cancer. Cancer Res 66: $1517-1525,2006$.

16. Rose SL: Notch signaling pathway in ovarian cancer. Int J Gynecol Cancer 19: 564-566, 2009.

17. Rahman MT, Nakayama K, Rahman M, Katagiri H, Katagiri A, Ishibashi T, Ishikawa M, Iida K, Nakayama S, Otsuki Y, et al: Notch 3 overexpression as potential therapeutic target in advanced stage chemoresistant ovarian cancer. Am J Clin Pathol 138: 535-544, 2012.

18. Sanchez GM, Re L, Giuliani A, Núñez-Sellés AJ, Davison GP and León-Fernández OS: Protective effects of Mangifera indica $\mathrm{L}$. extract, mangiferin and selected antioxidants against TPA-induced biomolecules oxidation and peritoneal macrophage activation in mice. Pharmacol Res 42: 565-573, 2000.

19. Dar A, Faizi S, Naqvi S, Roome T, Zikr-ur-Rehman S, Ali M, Firdous S and Moin ST: Analgesic and antioxidant activity of mangiferin and its derivatives: The structure activity relationship. Biol Pharm Bull 28: 596-600, 2005.
20. Guha S, Ghosal S and Chattopadhyay U: Antitumor, immunomodulatory and anti-HIV effect of mangiferin, a naturally occurring glucosylxanthone. Chemotherapy 42: 443-451, 1996.

21. Duang XY, Wang Q, Zhou XD and Huang DM: Mangiferin: A possible strategy for periodontal disease to therapy. Med Hypotheses 76: 486-488, 2011.

22. García-Rivera D, Delgado R, Bougarne N, Haegeman G and Berghe WV: Gallic acid indanone and mangiferin xanthone are strong determinants of immunosuppressive anti-tumour effects of Mangifera indica L. bark in MDA-MB231 breast cancer cells. Cancer Lett 305: 21-31, 2011.

23. Noratto GD, Bertoldi MC, Krenek K, Talcott ST, Stringheta PC and Mertens-Talcott SU: Anticarcinogenic effects of polyphenolics from mango (Mangifera indica) varieties. J Agric Food Chem 58: 4104-4112, 2010.

24. Chieli E, Romiti N, Rodeiro I and Garrido G: In vitro effects of Mangifera indica and polyphenols derived on ABCB1/Pglycoprotein activity. Food Chem Toxicol 47: 2703-2710, 2009.

25. Cheng P, Peng ZG, Yang $J$ and Song SJ: The effect of mangiferin on telomerase activity and apoptosis in leukemic K562 cells. Zhong Yao Cai 30: 306-309, 2007 (In Chinese).

26. Peng ZG, Luo J, Xia LH, Chen Y and Song SJ: CML cell line K562 cell apoptosis induced by mangiferin. Zhongguo Shi Yan Xue Ye Xue Za Zhi 12: 590-594, 2004 (In Chinese).

27. Percival SS, Talcott ST, Chin ST, Mallak AC, LoundsSingleton A and Pettit-Moore J: Neoplastic transformation of BALB/3T3 cells and cell cycle of HL-60 cells are inhibited by mango (Mangifera indica L.) juice and mango juice extracts. J Nutr 136: 1300-1304, 2006.

28. Chari NS, Pinaire NL, Thorpe L, Medeiros LJ, Routbort MJ and McDonnell TJ: The p53 tumor suppressor network in cancer and the therapeutic modulation of cell death. Apoptosis 14: 336-347, 2009.

29. Li H, Huang J, Yang B, Xiang T, Yin X, Peng W, Cheng W, Wan J, Luo F, Li H, et al: Mangiferin exerts antitumor activity in breast cancer cells by regulating matrix metalloproteinases, epithelial to mesenchymal transition, and $\beta$-catenin signaling pathway. Toxicol Appl Pharmacol 272: 180-190, 2013.

30. Shi W, Deng J, Tong R, Yang Y, He X, Lv J, Wang H, Deng S, Qi P, Zhang D, et al: Molecular mechanisms underlying mangiferininduced apoptosis and cell cycle arrest in A549 human lung carcinoma cells. Mol Med Rep 13: 3423-3432, 2016.

31. Ozols RF, Bundy BN, Greer BE, Fowler JM, Clarke-Pearson D, Burger RA, Mannel RS, DeGeest K, Hartenbach EM and Baergen R; Gynecologic Oncology Group: Phase III trial of carboplatin and paclitaxel compared with cisplatin and paclitaxel in patients with optimally resected stage III ovarian cancer: A Gynecologic Oncology Group study. J Clin Oncol 21: 3194-3200, 2003.

32. Luo X, Budihardjo I, Zou H, Slaughter C and Wang X: Bid, a $\mathrm{Bcl} 2$ interacting protein, mediates cytochrome $\mathrm{c}$ release from mitochondria in response to activation of cell surface death receptors. Cell 94: 481-490, 1998.

33. Worsley SD, Ponder BA and Davies BR: Overexpression of cyclin D1 in epithelial ovarian cancers. Gynecol Oncol 64: 189-195, 1997.

34. Yao J and Qian C: Inhibition of Notch3 enhances sensitivity to gemcitabine in pancreatic cancer through an inactivation of PI3K/Akt-dependent pathway. Med Oncol 27: 1017-1022, 2010.

35. Sarkar A, Sreenivasan Y, Ramesh GT and Manna SK: beta-DGlucoside suppresses tumor necrosis factor-induced activation of nuclear transcription factor kappaB but potentiates apoptosis. J Biol Chem 279: 33768-33781, 2004.

36. Rajendran P, Ekambaram G and Sakthisekaran D: Protective role of mangiferin against Benzo(a)pyrene induced lung carcinogenesis in experimental animals. Biol Pharm Bull 31: 1053-1058, 2008.

37. Allenspach EJ, Maillard I, Aster JC and Pear WS: Notch signaling in cancer. Cancer Biol Ther 1: 466-476, 2002.

38. Nickoloff BJ, Osborne BA and Miele L: Notch signaling as a therapeutic target in cancer: A new approach to the development of cell fate modifying agents. Oncogene 22: 6598-6608, 2003.

39. Wang M, Wu L, Wang L and Xin X: Down-regulation of Notch1 by gamma-secretase inhibition contributes to cell growth inhibition and apoptosis in ovarian cancer cells A2780. Biochem Biophys Res Commun 393: 144-149, 2010.

40. Drenzek JG, Seiler NL, Jaskula-Sztul R, Rausch MM and Rose SL: Xanthohumol decreases Notch1 expression and cell growth by cell cycle arrest and induction of apoptosis in epithelial ovarian cancer cell lines. Gynecol Oncol 122: 396-401, 2011. 
41. Liu MX, Siu MK, Liu SS, Yam JW, Ngan HY and Chan DW: Epigenetic silencing of microRNA-199b-5p is associated with acquired chemoresistance via activation of JAG1-Notch1 signaling in ovarian cancer. Oncotarget 5: 944-958, 2014.

42. Park JT, Chen X, Tropè CG, Davidson B, Shih IeM and Wang TL: Notch3 overexpression is related to the recurrence of ovarian cancer and confers resistance to carboplatin. Am J Pathol 177: 1087-1094, 2010

43. Gupta N, Xu Z, El-Sehemy A, Steed H and Fu Y: Notch3 induces epithelial-mesenchymal transition and attenuates carboplatininduced apoptosis in ovarian cancer cells. Gynecol Oncol 130 200-206, 2013.
44. McAuliffe SM, Morgan SL, Wyant GA, Tran LT, Muto KW, Chen YS, Chin KT, Partridge JC, Poole BB, Cheng KH, et al: Targeting Notch, a key pathway for ovarian cancer stem cells, sensitizes tumors to platinum therapy. Proc Natl Acad Sci USA 109: E2939-E2948, 2012

45. Choi JH, Park JT, Davidson B, Morin PJ, Shih Ie M and Wang TL: Jagged-1 and Notch3 juxtacrine loop regulates ovarian tumor growth and adhesion. Cancer Res 68: 5716-5723, 2008.

46. Chen X, Stoeck A, Lee SJ, Shih IeM, Wang MM and Wang TL: Jagged 1 expression regulated by Notch 3 and Wnt/ $\beta$-catenin signaling pathways in ovarian cancer. Oncotarget 1: 210-218, 2010. 